\title{
Impact of inorganic salts on behaviour of air bubbles in aqueous solutions
}

\author{
Danuta Szyszka ${ }^{1, a}$ \\ ${ }^{1}$ Department of Geoengineering, Mining and Geology, Wroclaw University of Science and Technology, Na Grobli 15, \\ 50-421 Wroclaw, Poland
}

\begin{abstract}
This paper comprises an analysis of solutions of such salts as: sodium chloride $\mathrm{NaCl}$, potassium chloride $\mathrm{KCl}$, sodium sulphate $\mathrm{Na}_{2} \mathrm{SO}_{4}$, ammonium chloride $\mathrm{NH}_{4} \mathrm{Cl}$, and hexylamine hydrochloride $\mathrm{C}_{6} \mathrm{H}_{15} \mathrm{~N} \cdot \mathrm{HCl}$. The objective of the paper was to determine the Critical Coalescence Concentration (CCC) of four inorganic and one organic salts. The obtained CCC values were similar to those already existing in literature. Also, in this paper the $\mathrm{CCC}$ values of investigated inorganic salts were compared in terms of their ionic strength. The results showed that, except $\mathrm{KCl}$, there was a relationship between $\mathrm{CCC}$ and ionic strength.
\end{abstract}

${ }^{a}$ Corresponding author: danuta.szyszka@pwr.edu.pl 